\title{
Preface: Approaches and methods to improve risk management in volcanic areas
}

\author{
P. Thierry ${ }^{1}$, M. Neri ${ }^{2}$, G. Le Cozannet ${ }^{1,3}$, P. Jousset ${ }^{1,4}$, and A. Costa ${ }^{5}$ \\ ${ }^{1}$ BRGM, French Geological Survey, 3 avenue Claude Guillemin, 45100 Orléans, France \\ ${ }^{2}$ Istituto Nazionale di Geofisica e Vulcanologia, Osservatorio Etneo, Sezione di Catania, Piazza Roma 2, 95125 Catania, Italy \\ ${ }^{3}$ Université Paris 1 Panthéon-Sorbonne, CNRS - UMR8591, Laboratoire de Géographie Physique, Paris, France \\ ${ }^{4}$ Helmholtz Centre GFZ Potsdam, Telegrafenberg, 14473 Potsdam, Germany \\ ${ }^{5}$ Istituto Nazionale di Geofisica e Vulcanologia, Sezione di Bologna, Via Donato Creti 12, 40128 Bologna, Italy \\ Correspondence to: P. Thierry (p.thierry@brgm.fr) and G. Le Cozannet (g.lecozannet@brgm.fr)
}

\begin{abstract}
Active volcanoes can generate multiple types of geological hazards. Besides syneruptive threats (e.g., lava, pyroclastic flows or ash fall), other adverse events such as landslides or lahars can occur at any time. To manage these threats efficiently, three key objectives must be jointly addressed: (1) improving prevention tools, through the collection and acquisition of data on hazards and risks, and its dissemination as maps and scenarios; (2) improving crisis management capabilities, based on monitoring and early warning systems, but also reliable communications systems; and (3) reducing people's vulnerability and developing recovery and resilience capabilities after an event has occurred. The special issue "Approaches and methods to improve risk management in volcanic areas" presents research results focusing on these three objectives. It demonstrates the utility of addressing them jointly, and particularly examines the case of volcanoes where little knowledge is available. These results were presented at the conference Integrated Approaches for Volcanic Risk Management (Hohenheim University, Stuttgart, 11/12 September 2012) of the European MIAVITA (MItigate and Assess risk from Volcanic Impact on Terrain and human Activities) project.
\end{abstract}

\section{Why a special issue on volcanic risk management?}

Volcanic eruptions are one of the most violent and dramatic agents of change on Earth. Besides their effects on climate at regional and global scales lasting up to several years and their potential to disrupt air traffic, local impacts of eruptions are the most significant. During the 20th century, such volcanic phenomena caused about 90000 fatalities and affected about
5.6 million people (Witham, 2005). As a contribution to the collective efforts to reduce these impacts, this special issue examines how risk management can be improved for volcanoes where little knowledge is available. The articles of this special issue are based on research results presented at the conference of the European research project MIAVITA (MItigate and Assess risk from Volcanic Impact on Terrain and human Activities) held at Hohenheim University, Stuttgart, 11/12 September 2012.

A major volcanic crisis is possible in Europe, especially since volcanoes like Campi Flegrei and Vesuvius are known to be potentially extremely dangerous. Effects of historic volcanic eruptions are well known and even hold a special place in the classical education of European pupils. However, it is uncertain whether the public is fully aware of the possibility of a renewal of explosive activity at these volcanoes, or if the institutions in charge of volcanic crisis management in $\mathrm{Eu}-$ rope are sufficiently prepared to face such situations: in the case of major eruptions, impacts may even extend beyond local and regional scales and may damage key infrastructures of our integrated economies. Moreover, despite all the efforts made by the European governments and the EU to render our societies more resilient to natural hazards, it is likely that the management of the crisis would require means that well exceed local and regional capacities. Hence, all European national states would be impacted and would need to intervene.

Conversely, in many developing countries such as Indonesia, where there are even geological records of very major eruptions in the past (e.g., Lavigne et al., 2013), the management of volcanic risk is often highly proficient due to the presence of numerous very active volcanoes and eruptions. 
In this respect, the technical, financial and human means to be dedicated to volcanic crisis differ in the two contexts.

\section{Integrated approaches toward risk management in volcanic areas}

To evaluate the mutual exchange of knowledge between actors of volcanic risk management in developed and developing countries, the European Commission launched a research and cooperation program in 2008, and, subsequently, funded the MIAVITA project. MIAVITA begins with the premise that efficient management requires the following three objectives to be jointly addressed:

- improving prevention tools, through the collection and acquisition of knowledge on hazard and risk and its dissemination through maps and scenarios for suitable actions and regulations;

- improving crisis management capabilities based on monitoring and early warning systems, but also reliable communication systems;

- reducing people's vulnerability and developing recovery and resilience capabilities after an event has occurred for both local communities and ecological systems.

To reach these objectives, at least two shifts in volcanic risk science paradigms needed to be made:

- First, the traditional focus on understanding volcanic processes should be extended to a broader perspective that encompasses all components of risks; this point is already widely acknowledged by the scientific community and the stakeholders of risk management.

- Second, development of methods for investigations and risk management should not be limited to the relatively small number of volcanoes most frequently in the spotlight: they must also be applicable to less known or poorly studied volcanoes, whether active or subject to other types of geological or hydrological hazards.

Indeed, little known volcanoes make up the vast majority of volcanoes on Earth; for example, Rouwet et al. (2014) highlight that only $20 \%$ of volcanic lakes have been studied so far. Only uncertain or undated evidence for past eruptions are available for $37 \%$ of the 1562 volcanoes considered active during the Holocene by the Global Volcanism Program of the Smithsonian Institution; this estimation corresponds to a very low level of knowledge: many of the volcanoes falling within the remaining $63 \%$ are considered presently as insufficiently known. For all these neglected areas, methods are needed to efficiently reduce risks.

Following these principles, a conceptual scheme has been conceived to represent an ideal situation, where all components of risk are equally addressed (Fig. 1).
This special issue presents articles focusing on approaches and methods aimed at improving risk management in volcanic areas where limited knowledge is available. They address key concepts shown in Fig. 1 as well as the information flow and links between them. Research and development are applied on three active volcanoes, the target study of MIAVITA: Mt. Cameroon (Cameroon), Fogo (Cape Verde) and Kanlaon (Philippines), plus an invited paper dedicated to Tristan da Cunha, a volcanic risk case study at one of the most remote places on Earth.

Most of these research results were presented as posters or talks at the conference Integrated Approaches for Volcanic Risk Management held at Hohenheim University, Stuttgart, 11/12 September 2012.

\section{New approaches and methods for volcanoes where limited knowledge is available}

Many volcanoes worldwide are currently inadequately monitored. This limits the ability of vulnerable communities to anticipate adverse eruptive events and thus take appropriate preparedness measures (upper-left box in Fig. 1). In this special issue, Faria and Fonseca (2014) describe such a scenario in the case of the Cape Verde archipelago. In 2011, they set up a seismic monitoring network on the islands of Fogo, Brava and Santo Antão, where most of the seismic activity is expected to occur. Their first findings indicate highly contrasting results among the islands: the highest seismicity is found at Fogo Island. Seismic events recorded at the islands of Brava and Santo Antão are largely attributed to volcanotectonic activity. While existing observations have not given any indication on the likelihood of subsequent events, they demonstrate the value of a nationwide seismic monitoring network at Cape Verde and the need to keep it going.

Knowledge of the hazard is crucial to prevent risks in volcanic areas. With this information, local authorities can make recommendations ranging from land use planning (to avoid new settlements in dangerous areas) to measures that reduce vulnerability (e.g., reinforcing buildings). This is indicated by the arrow connecting the central and upper-right boxes in Fig. 1. Ideally, information on the hazard is conveyed by maps that combine the intensity and frequency of each adverse event at each location. However, a number of adverse events related to volcanic activity to a greater or lesser degree can occur at volcanoes, such as lava or pyroclastic flows, lahars, tephra fall, gas emissions, earthquakes, landslides or flooding. This may then lead to producing a number of maps, each related to the various hazards and associated to different recommendations. To resolve this problem, Neri et al. (2013, in this special issue) propose a method to combine the multiple threats arising from different types of adverse events into one single map. The key point in the approach is to define a common intensity scale to compare the different level of threats. Neri et al. (2013, in this special issue) applied this 


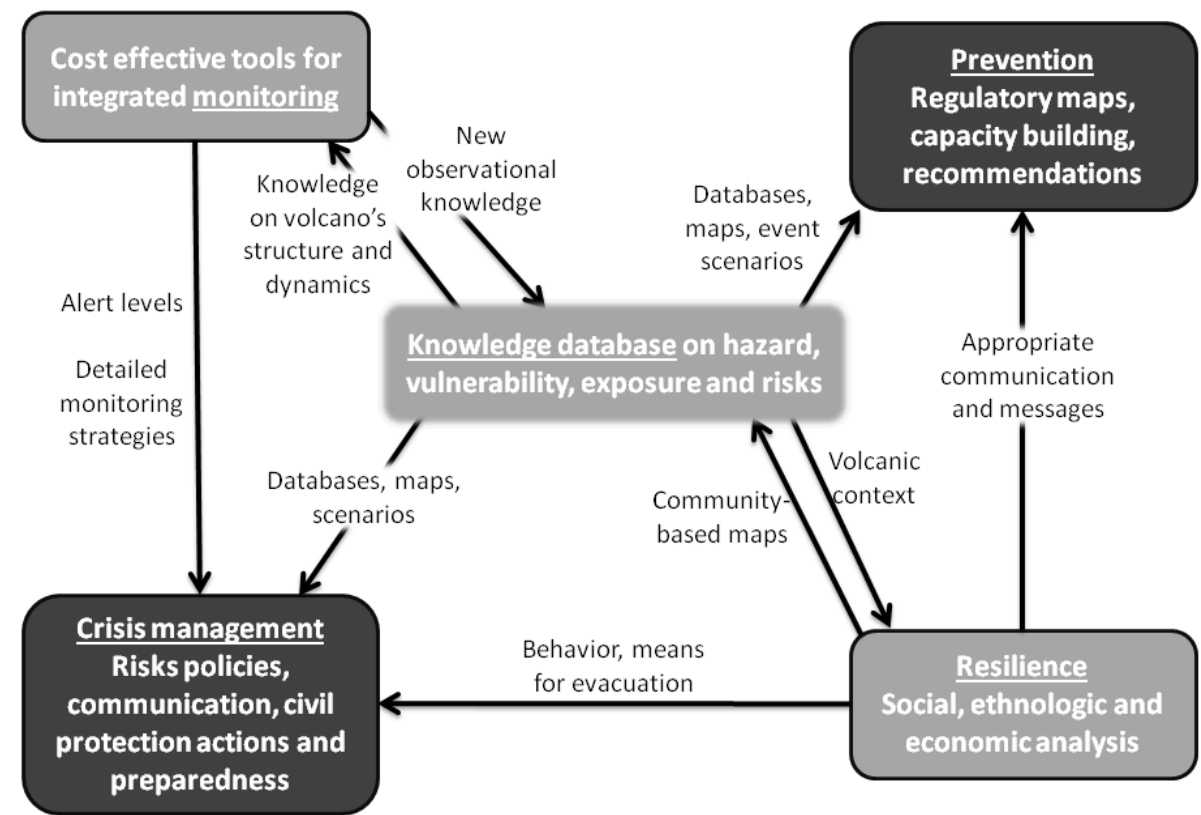

Figure 1. Conceptual frame of the various elements for integrated risk management (black boxes: institutional and operational actions; grey boxes: scientific and technical tools, arrows: information flows).

method to the Kanlaon volcano in the Philippines, using a combined approach with both a new high-resolution digital elevation model as well as field investigations. As a result, they present an updated hazard map for the volcano that combines the most important threats, namely lava, pyroclastic and mud flows (lahars). Given its flexibility, the method can be adapted to other lesser known volcanoes and may serve as a guideline when there are limited data.

Risk scenarios are another kind of tool to translate basic knowledge into useful information for preparedness (lowerleft and central boxes in Fig. 1). Gehl et al. (2013, in this special issue) have devised a tool to calculate damage caused by a given potential eruption, using eruptive scenarios fed by a hypothesized chronology of adverse events. Then, they use state of the art fragility functions (e.g., Jenkins et al., 2014) to evaluate the damage to vulnerable infrastructures (buildings, agriculture, roads, water or electrical networks). The tool was implemented at Mount Cameroon volcano, using data previously collected by Thierry et al. (2008), who formerly showed that risk scenarios can help authorities in charge of crisis management to prepare for future events.

Crisis management requires efficient communication tools (lower-left box in Fig. 1). One important requirement is to ensure that geophysical data collected on site can be transferred quickly and reliably to the analysis center. Reliable communication systems within a relatively remote area are vital. In this special issue, Fonseca et al. (2013) investigated this issue at Cape Verde islands. They devised a generic model for a telecommunication infrastructure at remote volcanoes and implemented an operational system that proved to be use- ful during the 2014 eruption (see next section). Their study provides useful recommendations for other remote volcanoes where the implementation of a monitoring system is planned.

One crucial element for disaster risk reduction is the development of smart tools to explore, visualize and interpret spatial data, with the end goal of informing decision-making efficiently; this is depicted by the central and lower-left boxes and by the arrow connecting them in Fig. 1. Le Cozannet et al. (2014, in this special issue) have achieved this taking into account numerous potential dangers at the Mount Cameroon volcano. A new web-based geographical information system (WebGIS) was developed by the group of hazard and risk analysts and managers, highlighting strengths and weaknesses of communication in poorly known areas, also characterized by populations with little access to information technologies.

Lopes Pereira et al. (2014 in this special issue) propose an innovative system to address this last mile challenge. Using a wireless sensor network, arrays of seismometers could be deployed to track ground movements. Once deployed on the volcano slopes, the array could help in characterizing parameters of volcano-seismic processes and mechanisms and their time evolution, leading to improved monitoring.

Two articles of this special issue address the human aspects of volcanic risk management (lower-right box of Fig. 1). Hicks et al. (2014, in this special issue) show that far from being the last issue, handling the human aspects of volcanic risk management as a priority may well prove beneficial. Their work was conducted at the Tristan da Cunha Islands, where a particularly isolated community (266 persons) has developed a highly specific culture over the $\sim 200$ years 
of its eventful history. Given that the patterns of future volcanic events were decidedly uncertain, they focused on the vulnerability and resilience of the community at risk. They conducted a planning exercise that led to take concrete risk reduction actions. It was followed up by the gradual implementation of a process to reduce risks, including monitoring measures. Starting with the human aspects, the research undertaken by Hicks et al. (2014, in this special issue) has addressed all topics schematized in Fig. 1, focusing primarily on those where the maximum benefits can be expected in terms of disaster risk reduction.

An experimental and shared three-dimensional mapping approach on volcanic risk was investigated at Fogo volcano (Cape Verde) by Teixier-Texeira et al. (2014, in this special issue); the aim was to assess the vulnerability of the community at risk in terms of livelihoods, access to resources and power relations between the local people and the institutions, to understand the degree and causes of vulnerability of the local people. The results are controversial: though the project has not led to an operational plan that takes on board local capacity due to the huge economic problems of those involved, it does create a dialogue between the local people and the administrative stakeholders (Natural Park administration, the National Civil Protection Service - SNPC, and the Municipality of Santa Catarina) who have participated actively in implementing the project.

\section{Synthesis and conclusion}

All the articles gathered in this special issue have not only provided new approaches or methods to address a specific aspect of volcanic risk management, but they also investigated how their contribution is helpful in the widest scheme described in Fig. 1. Obviously, the actual strategy to facilitate the emergence of an integrative approach differs from case to case. For example, monitoring has been considered a priority at Fogo, whereas - following previous intensive geological fieldwork - the dissemination of existing knowledge is considered important at Mount Cameroon. New scenario- and community-based approaches are also emerging to consider the fact that eruptions not only threaten lives and infrastructures on volcano summits and slopes, but can also have indirect effects at community, regional and national scales. All these research activities are finally contributing to converge toward an operational status as depicted in Fig. 1.

During or shortly after the MIAVITA project, two target volcanoes erupted: the Merapi in 2010 (Surono et al., 2012), and the Fogo in 2014. The project has supported another specific special issue of the Journal of Volcanology and Geothermal Research after the centennial eruption (October-November 2010) of the Merapi volcano (Jousset et al., 2013). Although fundamental knwoledge was the target, several other items of Fig. 1 were also adressed. In particular, risk studies were carried out (Mei et al., 2013; Picquout et al., 2013; Damby et al., 2013) and provide complementary insight to the integrative approach promoted by the project. In the case of Fogo (November 2014), the new monitoring infrastructure described in this special issue enabled raising the alert level 2 days before the eruption, so that the civil security could anticipate evacuations. Such disasters are dramatic due to their impacts on human lives and activities, as well as the numerous damages they cause. In both cases, the reduction of their adverse impacts has resulted from the action of Indonesian and Cape Verde volcano observatories and civil security. In this context, the support from the European 7th Framework Programme through the MIAVITA project has provided a useful contribution.

Risk management at volcanoes is complex, involving a wide range of issues: fundamental and applied geological knowledge, in situ and remote sensing observations for monitoring, fundamental knowledge, and also as tools in support of prevention, crisis management and resilience, as well as human sciences. This is particularly true in the most common situation where limited knowledge is available. This special issue has sought to illustrate that an efficient management of these threats requires the combination and coordination of many capabilities and instrumental techniques. It involves expertise in volcanology, geology, physics, signal processing and data analysis as well as agriculture and social sciences. We conclude by arguing that addressing all components of risk management and their interconnections within the same project is not only a timely research issue, but that it also has the potential to provide immediate benefits for communities exposed to volcanic risks.

Acknowledgements. This special issue has been supported by the MIAVITA project, financed by the European Commission under the 7th Framework Programme for Research and Technological Development, Area "Environment", Activity 6.1 "Climate Change, Pollution and Risks". We thank the NHESS editors and supporting staff for hosting this special issue. We also thank all participants to the MIAVITA project for their contributions, and Chris Newhall for very useful advice. We are grateful to the referees for reviewing the papers of this special issue, whose time and work contributed considerably to the quality of the paper. Finally, we thank Stephen Conway for proofreading this preface. 


\section{References}

Damby, D. E., Horwell, C. J., Baxter, P. J., Delmelle, P., Donaldson, P., Dunster, C., Fubini, B., Murphy, F. A., Nattrass, C., Sweeney, S., Tetley, T. D., and Tomatis, M.: The respiratory health hazard of tephra from the 2010 Centennial eruption of Merapi with implications for occupational mining of deposits, J. Volcanol. Geoth. Res., 261, 376-387, doi:10.1016/j.jvolgeores.2012.09.001, 2013.

Faria, B. and Fonseca, J. F. B. D.: Investigating volcanic hazard in Cape Verde Islands through geophysical monitoring: network description and first results, Nat. Hazards Earth Syst. Sci., 14, 485-499, doi:10.5194/nhess-14-485-2014, 2014.

Fonseca, J. F. B. D., Faria, B. V. E., Trindade, J., Cruz, G., Chambel, A., Silva, F. M., Pereira, R. L., and Vazão, T.: "Last mile" challenges to in situ volcanic data transmission, Nat. Hazards Earth Syst. Sci., 13, 3419-3428, doi:10.5194/nhess-13-34192013, 2013.

Gehl, P., Quinet, C., Le Cozannet, G., Kouokam, E., and Thierry, P.: Potential and limitations of risk scenario tools in volcanic areas through an example at Mount Cameroon, Nat. Hazards Earth Syst. Sci., 13, 2409-2424, doi:10.5194/nhess-13-24092013, 2013.

Hicks, A., Barclay, J., Simmons, P., and Loughlin, S.: An interdisciplinary approach to volcanic risk reduction under conditions of uncertainty: a case study of Tristan da Cunha, Nat. Hazards Earth Syst. Sci., 14, 1871-1887, doi:10.5194/nhess-141871-2014, 2014.

Jenkins, S. F., Spence, R. J. S., Fonseca, J. F. B. D., Solidum, R. U., and Wilson, T. M.: Volcanic risk assessment: Quantifying physical vulnerability in the built environment, J. Volcanol. Geoth. Res., 276, 105-120, doi:10.1016/j.jvolgeores.2014.03.002, 2014.

Jousset, P., Pallister, J., and Surono: The 2010 eruption of Merapi volcano, J. Volcanol. Geoth. Res., 261, 1-6, doi:10.1016/j.jvolgeores.2013.05.008, 2013.

Lavigne, F., Degeai, J. P., Komorowski, J. C., Guillet, S., Robert, V., Lahitte, P., Oppenheimer, C., Stoffel, M., Vidal, C., Surono, Pratomo, I., Wassmer, P., Hajdas, I., Hadmoko, D. S.. and de Belizal, E.: Source of the great AD 1257 mystery eruption unveiled, Samalas volcano, Rinjani Volcanic Complex, Indonesia, P. Natl. Acad. Sci., 110, 16742-16747, 2013.

Le Cozannet, G., Bagni, M., Thierry, P., Aragno, C., and Kouokam, E.: WebGIS as boundary tools between scientific geoinformation and disaster risk reduction action in volcanic areas, Nat. Hazards Earth Syst. Sci., 14, 1591-1598, doi:10.5194/nhess-141591-2014, 2014.
Lopes Pereira, R., Trindade, J., Gonçalves, F., Suresh, L., Barbosa, D., and Vazão, T.: A wireless sensor network for monitoring volcano-seismic signals, Nat. Hazards Earth Syst. Sci., 14, 3123 3142, doi:10.5194/nhess-14-3123-2014, 2014.

Mei, E. T. W., Lavigne, F., Picquout, A., de Bélizal, E., Brunstein, D., Grancher, D., Sartohadi, J., Cholik, N., and Vidal, C.: Lessons learned from the 2010 evacuations at Merapi volcano, J. Volcanol. Geoth. Res., 261, 348-365, doi:10.1016/j.jvolgeores.2013.03.010, 2013.

Neri, M., Le Cozannet, G., Thierry, P., Bignami, C., and Ruch, J.: A method for multi-hazard mapping in poorly known volcanic areas: an example from Kanlaon (Philippines), Nat. Hazards Earth Syst. Sci., 13, 1929-1943, doi:10.5194/nhess-13-19292013, 2013.

Picquout, A., Lavigne, F., Mei, E. T. W., Grancher, D., Noer, C., Vidal, C. M., and Hadmoko, D. S.: Air traffic disturbance due to the 2010 eruption of Merapi volcano, J. Volcanol. Geoth. Res., 261, 366-375, doi:10.1016/j.jvolgeores.2013.04.005, 2013.

Rouwet, D., Tassi, F., Mora-Amador, R., Sandri, L., and Chiarini, V.: Past, present and future of volcanic lake monitoring, J. Volcanol. Geoth. Res., 272, 78-97, doi:10.1016/j.jvolgeores.2013.12.009, 2014.

Surono, Jousset, P., Pallister, J., Boichu, M., Buongiorno, M. F., Budisantoso, A., Fidel Costa, Andreastuti, S., Prata, F., Schneider, D., Clarisse, L., Humaida, H., Sumarti, S., Bignami, C., Griswold, J., Carn, S., Oppenheimer, C., and Lavigne, F.: The 2010 explosive eruption of Java's Merapi volcano - A "100-year" event, J. Volcanol. Geoth. Res., 241-242, 121-135, doi:10.1016/j.jvolgeores.2012.06.018, 2012.

Texier-Teixeira, P., Chouraqui, F., Perrillat-Collomb, A., Lavigne, F., Cadag, J. R., and Grancher, D.: Reducing volcanic risk on Fogo Volcano, Cape Verde, through a participatory approach: which outcome?, Nat. Hazards Earth Syst. Sci., 14, 2347-2358, doi:10.5194/nhess-14-2347-2014, 2014.

Thierry, P., Stieltjes, L., Kouokam, E., Ngueya, P., and Salley, P. M.: Multi-hazard risk mapping and assessment on an active volcano: the GRINP project at Mount Cameroon, Nat. Hazards, 45, 429456, doi:10.1007/s11069-007-9177-3, 2008.

Witham, C. S.: Volcanic disasters and incidents: a new database, J. Volcanol. Geoth. Res., 148, 291-233, doi:10.1016/j.jvolgeores.2005.04.017, 2005. 